\title{
The 'Finch Report' and the transition to Open Access: Long term monitoring of progress in the United Kingdom
}

\author{
Michael Jubb \\ Director Research Information Network, London, UK
}

Progress monitoring requires reliable high-quality indicators on the key features of the changing landscape. In June 2012, the 'Finch Report' in Accessibility, Sustainability, Excellence: How to Expand Access to Research Publications called for progress monitoring in order to sustain the confidence of all concerned. ${ }^{1}$

It is essential that the configuration of the indicators, and the methodologies for data collection and analysis, are agreed between representatives of research funding bodies, scholarly publishers, and the research community. For this agreement, a common framework for defining and selecting indicators is required, as well as an understanding of what cannot be measured, whether it is for lack of data or methodological reasons.

In order to get an agreed set of indicators, we must consider who wants to know what, and why. Funders, public and private, want to know how effective their open access policies are. Is investment in changing the way research is published paying off? Universities and research institutes need to know how they can most effectively support the transition to open access. How will they organize and fund the transition? Publishers, including learned societies, must understand how the policies affect author relations and income streams: How can disruption for successful journals be minimized? Authors and readers want to know of the benefits and disadvantages of the new system. What changes in behaviour are required?

The lack of authoritative information about key aspects of the transition to open access was a key issue identified by the Finch Group when it reconvened in October 2013 to review progress in the implementation of the recommendations in its 2012 report. Routes to providing authoritative information then became the focus of a Research Information Network (RIN) Working Party on Monitoring Progress in the Transition to Open Access. ${ }^{2}$

Hence, I outline the Finch Group's further recommendations to remedy that problem. Next, I turn to the RIN Working Party and outline the general principles, which should underpin a monitoring framework. Thirdly, I highlight key issues that arise in three main areas: accessibility, financial sustainability,

\footnotetext{
${ }^{1}$ An overview and quick link to this Finch Group report and subsequent major documents is provided by the Research Information Network at http://www.researchinfonet.org/finch/quick-links/.

${ }^{2}$ Members of the RIN Working Group: Mayur Amin (Elsevier, for the Publishers Association), Simon Bell (British Library), Laura Bellingan (Society of Biology), Steven Hill (HEFCE), Neil Jacobs (Jisc), Michael Jubb (Research Information Network, Chair), Robert Kiley (Wellcome Trust), Valerie McCutcheon (University of Glasgow, for ARMA), David Prosser (Research Libraries UK), Wim van der Stelt (BioMedCentral, for the Publishers Association), Mari Williams (BBSRC, for RLUK). The report is available at http://www.researchinfonet.org/wp-content/uploads/2013/02/Report-final.pdf.
} 
and the quality of services for authors and readers. This is followed by suggestions on the governance structure and the road ahead.

\section{Finch Group review of progress}

When the Working Group on Expanding Access to Published Research Findings (the 'Finch Group') published its initial report in June 2012, it agreed to reconvene a year later to review progress in the implementation of its recommendations. In the meantime the bodies funding research and higher education were adopting new open access policies; there had been considerable debate about those policies, including enquiries at the House of Commons and the House of Lords; and researchers, universities and publishers had already begun to adjust their behaviour.

The Group's Review of Progress in Implementing the Recommendations of the Finch Report ${ }^{3}$ emphasised the original insight that for the foreseeable future a mixed economy would prevail. Even as open access publishing expands, green open access and expanded subscription access remain essential. The Group also restated the importance of the balanced package and of respecting the core interests of stakeholders during a transition process that will raise problems for all of them.

The Review found that there indeed had been considerable and very welcome progress in the implementation of its recommendations. But much of the evidence it gathered pointed to how little authoritative information was available on key aspects of the transition to open access in the UK (and globally); and it stressed the need for systematic gathering and analysis of data from a range of different parties in order to create the evidence base that is essential to the further development of policy in an effective fashion. Its key recommendation was that Universities UK (UUK), as the representative body for universities in the UK, should take the lead in establishing a formal structure to oversee work of this kind, as well as to co-ordinate the work of different agents and stakeholder groups, and to deal with problems of implementation as they arise.

In fact, even before the formal Finch Review had been completed, the Research Information Network (RIN) had established a small working party with representatives of the key stakeholder groups, to consider ways to develop a framework of indicators of progress in the transition to open access. In March 2014 it published the report Monitoring Progress in the Transition to Open Access. This report is one of the first issues being considered by the new UUK body.

\section{General principles}

Open access is a global issue, and the Finch report explicitly considered the global context when suggesting a mixed economy and balanced package. Global interdependence is reflected in adopting general principles, open to scrutiny at home and abroad, that underpin progress monitoring over the longer term. This secures the confidence of stakeholders in the UK and farther afield.

In order to develop its proposed framework of indicators, the working party convened by the RIN agreed five principles:

(1) Together define and prioritise key questions leading to an agreed set of indicators, protocols and data.

\footnotetext{
${ }^{3}$ http://www.researchinfonet.org/implementing-the-recommendations-of-the-finch-report/.
} 
(2) Assume collective responsibility for progress monitoring but stay neutral at all times.

(3) Ensure openness and transparency of indicators and data by making them freely accessible to all under a CC-BY license to use and scrutinize.

(4) Agree on a cost-effective route to monitoring.

(5) Establish regularity, preferably by reporting at annual intervals (monitoring is, after all, about analysing and assessing trends over time).

\section{Coverage of a framework of indicators}

The RIN working party focused its work on three main areas: accessibility, financial sustainability and quality of service. Indeed, these were the major themes of the Finch report, with quality of service understood to be a proxy for excellence.

\subsection{Accessibility}

The key question here is trends in the numbers and the proportions of the overall population of articles that are published or accessible on open access terms. More precisely, with the global number of published articles as benchmark and comparison, articles with at least one UK author should be counted under four headings, covering those:

- in fully-open access journals;

- on open access terms in hybrid journals;

- in journals that provide delayed access free of charge on the journal platform;

- accessible via repositories and other sites.

Gathering data for this indicator will depend on robot searches for samples of articles - using CrossRef and/or Scopus as reference databases. The RIN working party recommended taking samples at intervals of one, seven, thirteen and twenty-five months, corresponding to funders' maximally permissible embargo periods plus one month. Some manual checking would be necessary to ensure validity and consistency. Articles would be tracked across broad subject areas: humanities, social sciences, life sciences and medicine, and physical sciences and engineering. These are the main subject categories used by the UK Higher Education Funding Councils in their Research Excellence Framework for the assessment of research performance. Further subject breakdowns would require much bigger sample sizes to generate robust data.

Reinforcing the need for manual checks, there will be a need to address issues including illicit postings, version control, the timing of publications and license terms. The working party agreed after some discussion that the count should include illicit postings - where copies of articles are made available on the Internet even though the terms of the license, relating, for instance, to embargoes, forbid this; but that estimates of the numbers of illicit postings should also be made, based on checks of a sub-sample of the articles found. Version control means de-duplicating the different versions of any article, e.g. author's draft, accepted manuscript, and version of record. Timing is also critical because although journals are still mainly published as discrete issues, 'online first' means that articles appear continuously, with an obvious impact on the timing and length of embargoes. Data about when an article is first published is often not available, and in any case not standardized across the industry. On pragmatic grounds the working party agreed that the date of the journal issue should be taken as the date of publication. Finally, 
license terms data may be gathered automatically for Creative Commons licences, but not yet for all kinds of licences.

On the supply-side of accessibility, i.e. publishing, the main questions relate to trends in:

- publishers' embargo period length;

- levels of article-processing charges; and

- publishers' options for licensing.

Data should be tracked by using a stratified sample ${ }^{4}$ of UK authors' most popular journals for publication - using the same four broad subject categories.

\subsection{Usage}

Since one of the drivers for open access is the belief that it will lead to more usage, particularly by those who do not have free access following payment of a subscription, it would be highly desirable to gather data to examine whether and to what extent that proves to be the case. The RIN working party concluded, however, that collecting clear and authoritative usage data was not possible in any straightforward manner, at least not for the present.

\subsection{Financial sustainability}

On the issue of financial sustainability, universities and research funders have obvious concerns about costs. A key question relates therefore to trends in expenditure by funders and universities under four heads, with the first two by far the most important:

- The amounts paid in article processing charges and other publication charges, and the number of payments;

- Continuing subscription costs, and the number of journals subscribed to;

- The use of funders' grants as distinct from other sources of university income to pay APCs;

- The overall number of articles published in open access and the number deposited in repositories.

Methodologically, the RIN working party agreed that the best way forward would be to collect data from a stratified sample of UK universities. Active discussion with universities in the sample would be necessary to ensure that the data would be reliable and consistent. This approach would thus avoid costly - and probably ineffective - attempts to validate, and make consistent, data gathered and created in different ways across the whole university sector.

On the income side, i.e. publishers, the key question is what the impact will be on revenues. In more detail:

- What is the relationship between embargo periods and the sustainability of subscriptions?

- What market shares do different categories of publishers have?

- How effective are market and price signals?

- How many new entrants are there, and how easy is it to enter the market?

The RIN working party concluded, reluctantly, that there was no straightforward way to build indicators and collect data to answer such questions on a regular basis. This is not to say that these questions should not be studied. But they would require lengthy and complex study design and analysis.

\footnotetext{
${ }^{4}$ Stratified sampling means that the whole population is divided in to homogeneous but mutually exclusive subgroups that are collectively exhaustive before sampling. This improves the representativeness of the sample.
} 
The sustainability of open access for learned societies is an issue of great concern in the UK. There is a wide range of societies, and many of them play a key role in the life of researchers, in career development, and in research communication. Their dependence on publishing revenue varies but is often quite substantial. As regards publishing revenues, the same holds for publishers more generally. However, by survey sampling of learned societies income streams more generally, a better understanding of the importance of journal-related income may be developed.

\subsection{Quality of service}

The quality of services to authors is of critical importance. There is a widespread belief in the UK that the exceptional performance of its research base is closely related to the UK's role as a publishing hub, and the high-quality of service that researchers receive through the publishing process. Hence, a key question is whether the shift to open access has any implications for the quality of service provided to authors.

Fortunately, there are ways of tracking changes, for example by critical incident surveys of samples of UK authors to ascertain trends in levels of satisfaction and views on the quality of service. Other indicators could be:

- Time elapsed from submission to decision (in the four broad subject areas).

- Extent and types of revisions before acceptance for publication.

- Time from acceptance to publication.

Conjoint analysis could also be undertaken of the extent to which price, i.e. the level of the article processing charge, affects authors in their choice of journal.

For readers, the key question is what implications, if any, open access has for the quality and take-up of services provided by publishers. However, the working party saw no way of addressing this issue.

\section{Governance structure}

UUK has now established an Open Access Group in accordance with the recommendations of the Finch Group's Review of Progress. Its members are drawn from all relevant stakeholders, and it is currently considering how best to commission and oversee the work outlined in the RIN working party's report.

\section{Looking ahead}

Implementation of the Finch Group recommendations has progressed, but there is a need to establish systematic arrangements for gathering and analysing data on key aspects of the transition to open access. Those arrangements need to ensure collective responsibility from all the key stakeholder groups, openness and transparency, and cost-effectiveness (since it will not be possible to answer all the questions that one may wish to ask through a straightforward data-gathering exercise). Since monitoring is about trends, it is also critically important that data should be gathered regularly and on a consistent basis. These issues are now being addressed by the UUK Open Access Group, and we hope that work will begin soon. 